\title{
Article
}

\section{The Influence of Asymptomatic Hypermobility on Unanticipated Cutting Biomechanics}

Hanzlíková, Ivana, Richards, James, Athens, Josie and HebertLosier, Kim

Available at http://clok.uclan.ac.uk/37108/

Hanzlíková, Ivana, Richards, James ORCID: 0000-0002-4004-3115, Athens, Josie and Hebert-Losier, Kim (2021) The Influence of Asymptomatic Hypermobility on Unanticipated Cutting Biomechanics. Sports Health: A Multidisciplinary Approach, 13 (6). pp. 548-553. ISSN 1941-7381

It is advisable to refer to the publisher's version if you intend to cite from the work. http://dx.doi.org/10.1177/1941738121999063

For more information about UCLan's research in this area go to http://www.uclan.ac.uk/researchgroups/ and search for < name of research Group>.

For information about Research generally at UCLan please go to http://www.uclan.ac.uk/research/

All outputs in CLoK are protected by Intellectual Property Rights law, including Copyright law. Copyright, IPR and Moral Rights for the works on this site are retained by the individual authors and/or other copyright owners. Terms and conditions for use of this material are defined in the policies page.

\section{CLoK}

Central Lancashire online Knowledge www.clok.uclan.ac.uk

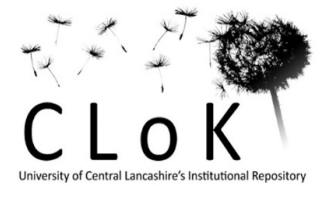




\title{
The influence of asymptomatic hypermobility on unanticipated cutting kinematics
}

\author{
Ivana Hanzlíkováa ${ }^{\mathrm{a}}$ Jim Richards ${ }^{\mathrm{b}}$, Josie Athens ${ }^{\mathrm{c}}$, Kim Hébert-Losier ${ }^{\mathrm{a}}$ \\ ${ }^{a}$ Division of Health, Engineering, Computing and Science, Te Huataki Waiora School of \\ Health, Adams Centre for High Performance, University of Waikato, New Zealand \\ ${ }^{\mathrm{b}}$ Allied Health Research Unit, University of Central Lancashire, United Kingdom \\ ${ }^{c}$ Department of Preventive and Social Medicine, University of Otago, New Zealand
}

\begin{abstract}
Background: Generalized joint hypermobility is an important risk factor for knee injuries, including to the Anterior Cruciate Ligament (ACL). Examining movement patterns specific to hypermobile individuals during sport-specific movements could facilitate development of targeted recommendations and injury prevention programs for this population.
\end{abstract}

Hypothesis: Asymptomatic hypermobile participants will present kinematics measures suggestive of a greater risk of non-contact knee or ACL injuries.

Study design: Cross-sectional study.

Level of evidence: 3

Methods: Forty-two (15 asymptomatic hypermobile and 27 non-hypermobile) individuals performed unanticipated side-step cutting on their dominant and non-dominant legs. Ankle, knee, hip, pelvis, and trunk angles in all planes of motion were collected during the first 100 milliseconds after initial contact using a three-dimensional infrared system. Pre-contact footground angles were also extracted. Data from hypermobile and non-hypermobile groups were compared using multiple regression models with sex as a confounder. When non-significant, 
the confounder was removed from the model. Effect sizes (Hedge's g) were calculated in the presence of significant between-group differences.

Results: Hypermobile individuals presented with lower minimum knee valgus angles with a mean difference of $3.5^{\circ}(P=0.032$, Hedge's $g=0.69)$ and greater peak knee external rotation angles with a mean difference of $-4.5^{\circ}(P=0.035$, Hedge's $g=0.70)$ during dominant leg cutting, and lower peak ankle plantarflexion angles with a mean difference of $4.5^{\circ}(P=0.027$, Hedge's $g=0.73$ ) during non-dominant leg cutting compared to non-hypermobile individuals.

Conclusions: Based on current scientific evidence, however, the identified differences are not crucial biomechanical injury risk factors that could predispose asymptomatic hypermobile individuals to non-contact knee or ACL injuries.

Clinical relevance: Further research is needed to highlight differences between hypermobility groups. Knowledge of the differences between these groups may change the physical activity recommendations, prevention of injury, and rehabilitation approaches.

Keywords: injury risk; Beighton score, Anterior Cruciate Ligament 


\section{Introduction}

Generalized joint hypermobility $(\mathrm{GJH})$ is characterized by increased movement in multiple joints beyond normal ranges expected in a given population ${ }^{6}$. The scientific literature has identified GJH as a risk factor for non-contact knee injuries, including to the Anterior Cruciate Ligament (ACL) $)^{30,44}$. GJH is usually a congenital, inherited disorder and therefore cannot be prevented $^{6}$. Neuromuscular and biomechanical factors also play a central role in non-contact lower extremity injuries; however, high injury-risk movement patterns are modifiable using training interventions ${ }^{27}$. Studies have shown that GJH may affect posture and movement; for example, hypermobile individuals demonstrate postural deviances of hip and trunk ${ }^{4}$, and altered movement patterns during stair climbing ${ }^{28}$ and gait ${ }^{11,12,34,40}$ compared to nonhypermobile individuals.

None of the previous studies explored three-dimensional (3D) kinematics of hypermobile individuals during sport-specific movements associated with high risk of non-contact knee and ACL injury. The identification of movement patterns specific to hypermobile individuals during sport-specific high injury risk movements could facilitate the development and implementation of targeted recommendations, exercises, and injury prevention programs for this population. Furthermore, a recent framework for the classification of GJH suggests dividing hypermobile individuals into three categories: individuals with asymptomatic joint hypermobility, individuals with a well-defined syndrome associated with joint hypermobility, and individuals with symptomatic joint hypermobility ${ }^{6}$. Most published studies have explored movement patterns in children, symptomatic hypermobile individuals, or individuals with inherited well-defined disorders. There is currently a lack of evidence concerning the asymptomatic hypermobile population ${ }^{11,12,34}$. 
Therefore, the aim of this study was to compare unanticipated side-step cutting kinematics between asymptomatic hypermobile and non-hypermobile participants. We hypothesized that asymptomatic hypermobile participants would present kinematic measures suggestive of a greater risk of non-contact knee or ACL injuries, such as greater knee valgus motion, greater lateral trunk flexion motion, and less knee flexion during unanticipated cutting.

\section{Methods}

\subsection{Participants}

This study aimed to test a total of 15 individuals with GJH based on sample sizes of previous studies exploring differences in biomechanical measures between adult participants with GJH (12 to 17 participants) and healthy controls (12 to 20 participants ${ }^{12,40}$. Given that participants were not screened for GJH prior to participation, this resulted in a total sample size of 42 individuals participating in this study (15 with GJH and 27 controls).

Participants were recruited through personal contacts, institutional e-mail lists and online forums, advertisements to local sport clubs, advertisement on social media, and word of mouth. The inclusion criteria were regular participation in a team sport that involved cutting and being free from any injury or illness that had prohibited or limited physical activity in the 6 months prior to testing. A history of a previous injury or surgery was not an exclusion criterion. Only asymptomatic hypermobile or non-hypermobile participants were eligible; therefore, participants with known diagnosis of medical syndromes associated with joint hypermobility, e.g., Ehlers Danlos syndrome and Marfan syndrome, or participants with symptomatic joint hypermobility were excluded. The University of Waikato Human Research Ethics Committee approved the study protocol [HREC(Health)2018\#27], which adhered to the Declaration of Helsinki. All participants signed a written informed consent document prior to participating. 


\subsection{Experimental procedure}

Participants were familiarized with the experimental protocol and all testing was completed in one session. After completing the baseline questionnaire and the self-administered short-form International Physical Activity Questionnaire ${ }^{8}$, an experienced physiotherapist recorded Beighton scores following a standardized protocol using a goniometer ${ }^{43}$. The Beighton score is a major criterion used in diagnosing GJH, and has been shown to be a valid and reliable diagnostic tool ${ }^{32}$. In this study, sex and age-specific cut-off scores to identify hypermobile individuals based on Singh et al. ${ }^{41}$ were used. The cut-off score of $\geq 5$ points was used for females and $\geq 4$ points for males. After recording the Beighton scores, an unanticipated sidestep cutting maneuver was tested. For the side-step cutting maneuver, participants started five meters in front of the target cutting area. When the participant moved within the target area, timing gates (Swift Performance SpeedLight ${ }^{\mathrm{TM}}$ ) triggered one of two lights in a randomized order to signal the cutting direction, Figure 1. During cutting, participants were required to stay between two lines that were taped on the floor, which indicated a cutting angle between $60^{\circ}$ and $90^{\circ}$ (Figure 1). A minimum approach speed of $3.5 \mathrm{~m} / \mathrm{s}$ at the penultimate foot contact was required based on previous studies to mimic a typical game setting ${ }^{35}$. After a familiarization period of on average two attempts, each participant completed three successful repetitions of side-step cutting maneuvers on the dominant and non-dominant legs. For right-leg dominant participants, cutting to the left side represented dominant leg cutting and to the right side represented non-dominant leg cutting. The Perceived Recovery Status Scale was used to monitor subjective ratings of recovery ${ }^{26}$. To ensure sufficient recovery times between trials, participants needed to self-report ratings $\geq 7$ before starting the next trial; else, the rest periods were extended. Participants wore their own sport shoes for testing. 


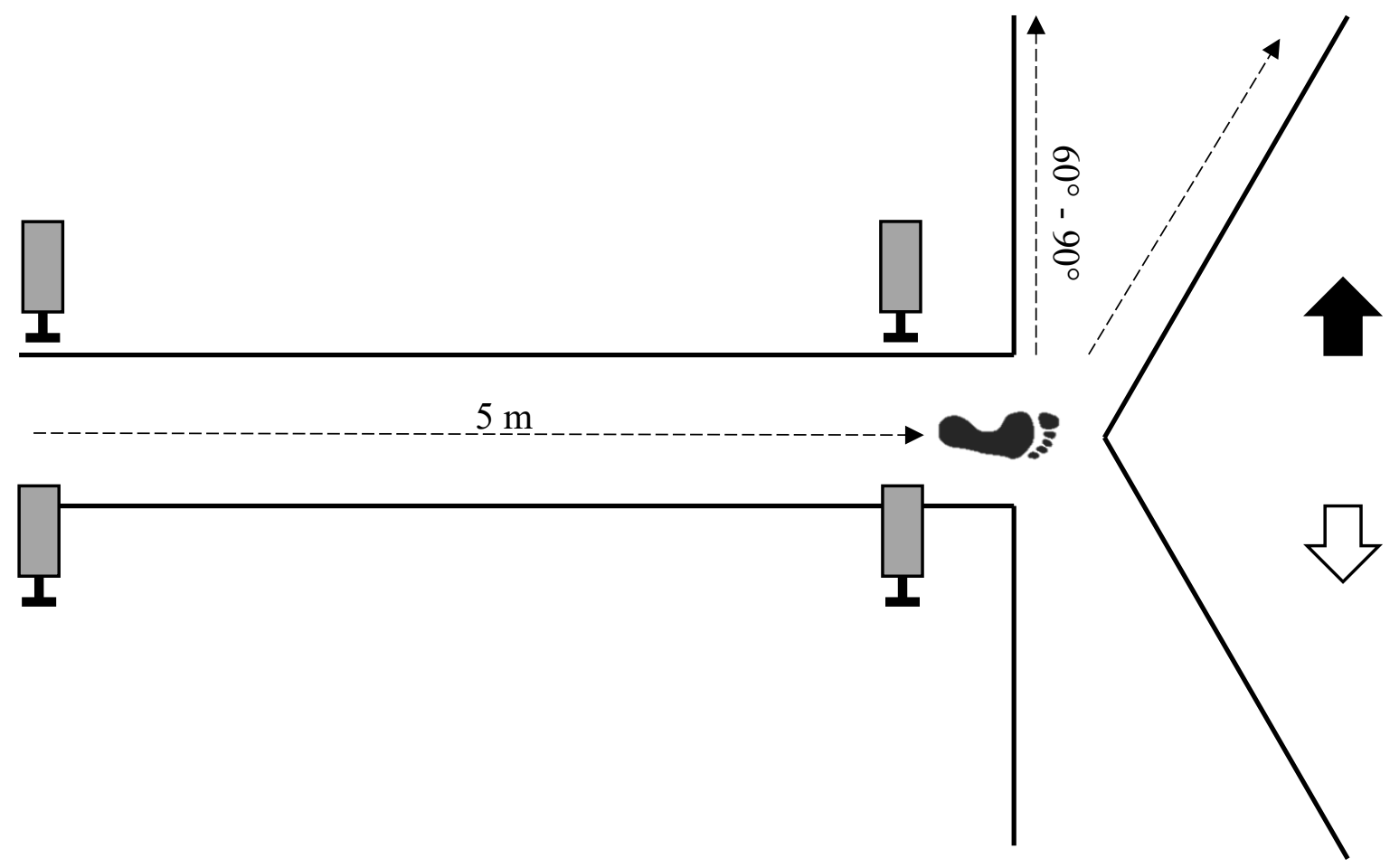

Figure 1. Scheme of unanticipated side-step cutting maneuver.

\subsection{Instrumentation}

Whole-body motion was monitored during the cutting maneuvers using an 8-camera Oqus 700 3D motion capture system at $200 \mathrm{~Hz}$ and the Qualisys Track Manager software version 2019.1 (Qualisys AB®, Gothenburg, Sweden). Forty-two $12.5 \mathrm{~mm}$ retroreflective markers and five clusters were taped onto the skin and shoes, which were modelled using the Calibrated Anatomical System Technique ${ }^{5}$ with an additional cluster placed on the right side of the pelvis to improve segment tracking, Figure 2. 


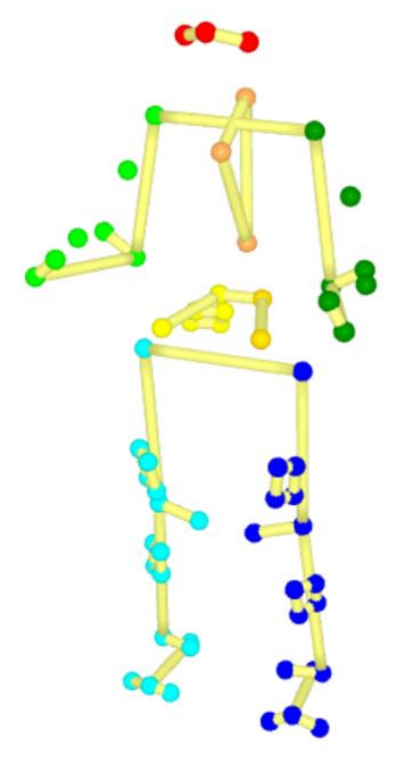

Figure 2. Marker placement.

\subsection{Data processing}

The raw data were exported to the.$c 3 d$ format and processed using Visual3D Professional ${ }^{\mathrm{TM}}$ software version 6.01.36 (C-Motion Inc., Germantown, Maryland, USA). From the reference set of markers, a full-body biomechanical model with six degrees of freedom at each joint and 13 rigid segments was constructed, with the local coordinates of all body segments derived from a 5-seconds static trial captured prior to the cutting maneuver. Any gaps in the marker data less than 10 frames were interpolated using a third order polynomial fit algorithm. Subsequently, the marker data were filtered using a fourth order low-pass Butterworth filter with a cut off frequency of $15 \mathrm{~Hz}^{16}$.

Kinematic parameters were calculated using an XYZ cardan sequence equivalent to the joint coordinate system proposed by Grood and Suntay ${ }^{14}$. Ankle, knee, hip, pelvis, and trunk angles in all three planes of motion were extracted from the first 100 milliseconds after initial contact (minimum, maximum, and range values) and foot-ground angles in all three planes of motion one frame before initial contact to explore pre-landing strategy ${ }^{17}$. The timeframe of 100 milliseconds after initial contact was chosen as this has been reported to be the time within 
which ACL injuries are most likely to occur ${ }^{24}$. Initial contact was defined as the instance when the cutting-leg foot center of gravity acceleration in the vertical plane of the lab coordination system $(z)$ reached a maximum value. Furthermore, the pelvis center of gravity velocity at initial contact and cutting angle during the cutting maneuver were extracted to quantify cutting performance. The directionality and interpretation of joint movements are presented in Appendix Table A1.

\subsection{Statistical analysis}

Joint angle data were exported to Excel where the values from three trials were averaged, which were then used for further processing. Given that our data showed significant differences related to leg dominance during cutting maneuvers, dominant and non-dominant leg cutting was analyzed separately. Mean \pm standard deviation, median (interquartile range), and range (minimum to maximum) values were calculated from the descriptive and biomechanical data to describe the hypermobile and non-hypermobile groups based on variable type. Two-tailed $t$ tests with unequal variance or Mann-Whitney U tests were carried out to investigate differences in demographic characteristics of the subgroups analyzed. A multiple linear regression model was used to compare the kinematic variables between the hypermobile and non-hypermobile groups with sex as a confounder. We controlled for sex due to the significant differences previously reported in cutting maneuvers ${ }^{2}$. When the sex confounder was not significant it was removed from the model. For statistically significant differences between hypermobile and non-hypermobile groups, mean differences with $95 \%$ confidence intervals and corresponding effect sizes (Hedge's $g$ ) were calculated. Note that no analysis was performed if only the sex confounder was significant. Thresholds for interpreting the magnitude of Hedge's $g$ were 0.20, 0.50 , and 0.80 for small, moderate, and large effects, respectively ${ }^{25}$, with effect sizes $<0.20$ considered trivial. The statistical significance level was set at $\alpha \leq 0.05$ for all analyses. All 
statistics were computed using Microsoft ${ }^{\circledR}$ Excel $^{\circledR}$ for Office 365 MSO and RStudio ${ }^{\circledR}$ Version 1.1.463 with $\mathrm{R}$ version 3.5.2.

\section{Results}

A sample of 42 participants, 25 males and 17 females, participated in the study (Table 1). A significant difference for Beighton scores was seen between the hypermobile and nonhypermobile groups $(P<0.001$, Table 1$)$. The majority of participants $(93 \%)$ were right-leg dominant, assessed by the preferred leg when kicking a ball. According to the International Physical Activity Questionnaire, the level of physical activity was high for 53\% and moderate for $47 \%$ of the hypermobile participants. The level of activity for non-hypermobile participants was high, moderate, and low in $63 \%, 33 \%$, and $4 \%$ of participants, respectively. From our sample, $31 \%$ of participants played soccer, $26 \%$ rugby, $17 \%$ ultimate Frisbee, $14 \%$ netball, $7 \%$ basketball, and 5\% field hockey. Participants' level of engagement with sport was 55\% club level, $21 \%$ recreational, $17 \%$ national level, and $7 \%$ school level.

Table 1. Participant characteristics. Values are mean \pm standard deviation and median (interquartile range).

\begin{tabular}{|c|c|c|c|c|c|}
\hline & \multirow{2}{*}{ All } & \multicolumn{2}{|c|}{ Hypermobile $(n=15)$} & \multicolumn{2}{|c|}{ Non-hypermobile $(n=27)$} \\
\hline & & Males & Females & Males & Females \\
\hline$n$ & 42 & 8 & 7 & 17 & 10 \\
\hline Age (years) & $23.0 \pm 4.8$ & $22.3 \pm 5.1$ & $24.4 \pm 7.1$ & $24.2 \pm 3.6$ & $20.6 \pm 4.1$ \\
\hline Height (cm) & $176.9 \pm 9.0$ & $180.1 \pm 4.7$ & $166.6 \pm 7.5$ & $183.2 \pm 6.9$ & $170.7 \pm 4.3$ \\
\hline Mass (kg) & $76.6 \pm 14.4$ & $82.7 \pm 11.0$ & $59.3 \pm 5.6$ & $86.1 \pm 12.4$ & $66.3 \pm 6.3$ \\
\hline BMI $\left(\mathrm{kg} / \mathrm{m}^{2}\right)$ & $24.3 \pm 3.1$ & $25.4 \pm 2.4$ & $22.1 \pm 2.7$ & $25.6 \pm 3.3$ & $22.7 \pm 1.8$ \\
\hline $\begin{array}{l}\text { Physical activity } \\
\text { (hours per week) }\end{array}$ & $6.7 \pm 4.4$ & $8.4 \pm 6.4$ & $5.2 \pm 3.4$ & $7.1 \pm 4.5$ & $5.5 \pm 2.3$ \\
\hline $\begin{array}{l}\text { Physical activity } \\
\text { (times per week) }\end{array}$ & $3(4)$ & $5(5)$ & $2(2)$ & $4(2)$ & $3(3)$ \\
\hline
\end{tabular}




\section{Years practising}

cutting sport

Beighton score

(points)
$10.5 \pm 6.2$

$3(2)$
$12.8 \pm 6.4$

$5(1)^{*}$
$5.1 \pm 4.8$

$8(1)^{*}$

$12.2 \pm 6.3$

$9.5 \pm 5.0$

Abbreviations: BMI, body mass index; $n$, number of participants

Hypermobile, Beighton score $\geq 4$ points for males and $\geq 5$ points for females; non-hypermobile, Beighton score $<4$ point for males and $<5$ points for females.

* Significant difference (Mann-Whitney U test $P$-value $<0.001$ ) between hypermobile and non-hypermobile groups

Overall, the mean cutting angle was $58.3 \pm 9.8^{\circ}$ and cutting speed at initial contact was $3.4 \pm$ $0.5 \mathrm{~m} / \mathrm{s}$. Mean \pm standard deviation values of kinematic variables for the two groups during side-step cutting maneuvers are presented in Appendix Table A2. During dominant leg cutting maneuvers, both groups held their knees in a valgus position, with the hypermobile group having lower minimum knee valgus angles (mean difference $3.5^{\circ}[0.3$ to 6.8$], P=0.032$, Hedge's $g=0.69$ ) compared to the non-hypermobile group. During dominant leg cutting, hypermobile group presented with greater peak knee external rotation angles with a mean difference of $-4.5^{\circ}[-8.5$ to -0.4$](P=0.035$, Hedge's $g=0.70)$ when compared to the nonhypermobile group. During non-dominant leg cutting maneuvers, the hypermobile group presented lower peak ankle plantarflexion angles with a mean difference of $4.5^{\circ}$ [0.5 to 8.4], $(P=0.027$, Hedge's $g=0.73)$ compared to the non-hypermobile group. 


\section{Discussion}

The purpose of this study was to compare the kinematics of cutting maneuvers between asymptomatic hypermobile and non-hypermobile participants. Despite significant and moderate differences in cutting kinematics identified between the two groups, based on current evidence $^{3,7,13,18,38}$, these kinematic variables do not seem to play crucial roles in non-contact knee and ACL injury mechanisms.

According to our results, the minimum knee valgus angle during the dominant leg cutting maneuvers was significantly different between hypermobile $\left(-0.5^{\circ} \pm 4.8^{\circ}\right)$ and nonhypermobile $\left(-4.0^{\circ} \pm 5.1^{\circ}\right)$ groups. The peak knee valgus angle is a well-recognized risk factor for ACL injuries ${ }^{18,19}$, however the minimum knee valgus angle has not been associated with injury risk. Besides of greater knee valgus angle, we hypothesized greater lateral trunk flexion and lesser knee flexion angles in the hypermobile group. However, in contradiction to our hypothesis, these variables were not significant different between groups.

The peak knee external rotation angles were significantly greater for the hypermobile compared to the non-hypermobile group during dominant leg cutting maneuvers. Substantial external rotation of the tibia together with knee valgus can cause impingement of the ACL against the intercondylar notch and increase the strain in the $\mathrm{ACL}^{3}$. This impingement is far more common when the knee is in a hyperextended position and can cause a midsubstance tear of the ACL. That said, the majority of sport-related non-contact ACL injuries occur in a partially-flexed knee position and ruptures are mostly located closer to the femoral attachment site ${ }^{3}$. Therefore, greater peak external rotation angles of the tibia are not crucial biomechanical injury risk factors that could predispose asymptomatic hypermobile individuals to non-contact ACL injuries in this particular task, especially given the knee flexion angles observed (mean values $\geq 25^{\circ}$ across groups, Appendix Table A2). 
During non-dominant leg cutting, the hypermobile group had lower peak ankle plantarflexion angles compared to the non-hypermobile group. Ankle dorsiflexion range of motion is associated with an increased sagittal plane displacement during jump-landing tasks and a softer landing technique ${ }^{20}$. However, to the authors' knowledge there are no studies exploring how limited ankle dorsiflexion or plantarflexion influence the biomechanics of cutting maneuvers. Several studies have highlighted the effect of foot strike angle on lower extremity biomechanics during cutting maneuvers ${ }^{9,46}$. More specifically, fore foot strike was associated with a smaller knee valgus angle, greater muscle activity of hamstrings, and greater energy absorption at the ankle than at the knee; which altogether suggests a lower risk of ACL injury ${ }^{9,46}$. However, foot-ground angles were similar between hypermobile and non-hypermobile participants tested in our study. Based on current evidence, we cannot conclude if the lower peak ankle plantarflexion angles found in the hypermobile group tested during the first 100 milliseconds of cutting can contribute to the higher knee injury risk reported in this population ${ }^{30,44}$.

Given that hypermobility is a risk factor for non-contact knee and ACL injuries ${ }^{30,44}$ and sidestep cutting maneuvers are a high risk task for knee injuries, we anticipated observing a greater number of significant differences between the two groups, including peak knee valgus, lateral trunk flexion, and knee flexion. The difference between study outcomes and our hypotheses is likely to be due to the population tested. Most previous studies exploring movement of hypermobile individuals recruited children ${ }^{11,22,23}$, symptomatic individuals ${ }^{40}$, or individuals with well-defined disorders ${ }^{12,34}$. These studies found that hypermobile individuals present reduced semitendinosus activation during a Single Leg Hop for a Distance test ${ }^{23}$, altered muscle activation during isometric knee flexion and extension ${ }^{22}$, impaired balance ${ }^{34}$, increased fall frequency ${ }^{34}$, and altered movement during gait ${ }^{11,12,34,40}$. Based on the authors' knowledge, only two studies have specifically involved asymptomatic hypermobile individuals ${ }^{15,28}$. Luder et al. ${ }^{28}$ found that hypermobile females had lower electromyographic activity of the quadriceps 
during stair ascent and descent compared to non-hypermobile controls. However, when hypermobile females were divided into symptomatic and asymptomatic hypermobile groups, these differences remained significant between the symptomatic hypermobile group and control group only. Moreover, Hanzlíková and Hébert-Losier ${ }^{15}$ did not find any difference in gross movement patterns during jump-landing tasks between asymptomatic hypermobile and non-hypermobile participants. It may be that the asymptomatic hypermobile individuals examined in our study used different neuromuscular control strategies than symptomatic hypermobile participants and hypermobile participants with Ehlers-Danlos syndrome explored in previous studies. Hypermobile individuals without symptoms may be fully adapted to their condition and use strategies to actively stabilize their hypermobile joints during dynamic tasks, which may explain to some extent why they do not suffer from chronic pain, fatigue, micro traumas, and other symptoms associated with hypermobility. Furthermore, other symptoms associated with GJH may play a more important role in movement and injury risk than increased mobility beyond normal limits. For example, it is well know that chronic widespread musculoskeletal pain, common in connective tissue disorders, leads to changes in movement patterns and inhibition of related muscle activity, and therefore may contribute to injury to a larger extent ${ }^{21}$.

Further research is needed to highlight any differences and clinical implications of any differences between symptomatic and asymptomatic hypermobile individuals as well as individuals with disorders affecting connective tissue. Knowledge of the differences between these groups may change the physical activity recommendations, prevention of injury, and rehabilitation approaches. For example, some research advises hypermobile individuals to participate in non-contact activities only, such as Pilates, Tai Chi, swimming, some forms of yoga, and dance, and to avoid physical exertion at a higher than normal rhythm ${ }^{10,39}$. On the other hand, Murray ${ }^{29}$ recommended full participation in any sporting activities for pain free 
hypermobile individuals. Furthermore, scientific evidence indicate that joint hypermobility is coupled with reduced joint proprioception ${ }^{42}$ and muscle strength ${ }^{33,36}$. Therefore, these two areas appear to play an important role in prevention and rehabilitation approaches targeting hypermobile individuals. However, it remains unknown whether proprioception and muscle strength are affected to the same extent in all three hypermobility categories as defined by Castori et al. ${ }^{6}$.

\section{Limitations}

Advancing age leads to a decline in range of motion of joints up to $57 \%$ in the elderly ${ }^{1,37}$. Moreover, sport activity may result in positive adaptation and improve movement control of asymptomatic hypermobile individuals. Therefore, we caution that our sampled population of young active individuals may limit the generalizability of our findings to older or younger populations, or more or less active groups. Even though 3D motion capture system is considered "gold standard" in assessing human movement non-invasively with accuracy of less than $1 \mathrm{~mm}$ in marker tracing ${ }^{45}$, error in marker placement and soft-tissue artifact may result in error of measurement up to $40 \mathrm{~mm}^{31}$. Previous research has shown significant differences in

joint moments between hypermobile and non-hypermobile individuals ${ }^{40}$, however, the kinetics of cutting maneuvers could not be examined in our study. Furthermore, the underlying neuromuscular control during side-step cutting maneuvers may differ between hypermobile and non-hypermobile individuals, although electromyography was not used as part of this study to confirm differences in muscle recruitment and activation patterns.

\section{Conclusion}

Although some significant differences in the kinematics of unanticipated cutting maneuvers were identified between asymptomatic hypermobile and non-hypermobile groups, based on 
current evidence, these kinematic variables do not seem to play crucial roles in non-contact knee and ACL injury mechanisms. 


\section{References}

1. Beighton P, Solomon L, Soskolne C. Articular mobility in an African population. Ann Rheum Dis. 1973;32(5):413-418.

2. Benjaminse A, Gokeler A, Fleisig GS, Sell TC, Otten B. What is the true evidence for gender-related differences during plant and cut maneuvers? A systematic review. Knee Surg Sports Traumatol Arthrosc. 2011;19(1):42-54.

3. Boden BP, Sheehan FT, Torg JS, Hewett TE. Non-contact ACL injuries: mechanisms and risk factors. J Am Acad Orthop Surg. 2010;18(9):520.

4. Booshanam DS, Cherian B, Joseph CPA, Mathew J, Thomas R. Evaluation of posture and pain in persons with benign joint hypermobility syndrome. Rheumatol Int. 2011;31(12):1561-1565.

5. Cappozzo A, Catani F, Della Croce U, Leardini A. Position and orientation in space of bones during movement: anatomical frame definition and determination. Clin Biomech. 1995;10(4):171-178.

6. Castori M, Tinkle B, Levy H, Grahame R, Malfait F, Hakim A. A framework for the classification of joint hypermobility and related conditions. Am J Med Genet C Semin Med Genet. 2017;175(1):148-157.

7. Cowley HR, Ford KR, Myer GD, Kernozek TW, Hewett TE. Differences in neuromuscular strategies between landing and cutting tasks in female basketball and soccer athletes. J Athl Train. 2006;41(1):67.

8. Craig CL, Marshall AL, Sjorstrom $\mathrm{M}$, et al. International physical activity questionnaire: 12-country reliability and validity. Med Sci Sports Exerc. 2003;35(8):1381-1395. 
9. David S, Mundt M, Komnik I, Potthast W. Understanding cutting maneuvers-the mechanical consequence of preparatory strategies and foot strike pattern. Hum Movement Science. 2018;62:202-210.

10. Diaz MA, Estevez EC, Guijo PS. Joint hyperlaxity and musculoligamentous lesions: study of a population of homogeneous age, sex and physical exertion. Rheumatology. 1993;32(2):120-122.

11. Fatoye FA, Palmer S, Van der Linden ML, Rowe PJ, Macmillan F. Gait kinematics and passive knee joint range of motion in children with hypermobility syndrome. Gait Posture. 2011;33(3):447-451.

12. Galli M, Cimolin V, Rigoldi C, et al. Gait strategy in patients with Ehlers-Danlos syndrome hypermobility type: a kinematic and kinetic evaluation using 3D gait analysis. Res Dev Disabil. 2011;32(5):1663-1668.

13. Greska EK, Cortes N, Ringleb SI, Onate JA, Van Lunen BL. Biomechanical differences related to leg dominance were not found during a cutting task. Scand J Med Sci Sports. 2017;27(11):1328-1336.

14. Grood ES, Suntay WJ. A joint coordinate system for the clinical description of threedimensional motions: application to the knee. J Biomech Eng. 1983;105(2):136-144.

15. Hanzlíková I, Hébert-Losier K. Do asymptomatic generalised hypermobility and knee hyperextension influence jump landing biomechanics? European Journal of Physiotherapy. 2020. Advance online publication. doi: $10.1080 / 21679169.2020 .1769721$

16. Hanzlíková I, Richards J, Hébert-Losier K, Smékal D. The effect of proprioceptive knee bracing on knee stability after Anterior Cruciate Ligament reconstruction. Gait Posture. 2019;67:242-247. 
17. Harry JR, Silvernail JF, Mercer JA, Dufek JS. Comparison of pre-contact joint kinematics and vertical impulse between vertical jump landings and step-off landings from equal heights. Hum Movement Science. 2017;56:88-97.

18. Hewett TE, Ford KR, Hoogenboom BJ, Myer GD. Understanding and preventing ACL injuries: current biomechanical and epidemiologic considerations-update 2010. N Am J Sports Phys Ther. 2010;5(4):234-251.

19. Hewett TE, Myer GD, Ford KR, et al. Biomechanical measures of neuromuscular control and valgus loading of the knee predict anterior cruciate ligament injury risk in female athletes: a prospective study. Am J Sports Med. 2005;33(4):492-501.

20. Hoch MC, Farwell KE, Gaven SL, Weinhandl JT. Weight-bearing dorsiflexion range of motion and landing biomechanics in individuals with chronic ankle instability. J Athl Train. 2015;50(8):833-839.

21. Hodges PW, Tucker K. Moving differently in pain: a new theory to explain the adaptation to pain. Pain. 2011;152(3):S90-S98.

22. Jensen BR, Sandfeld J, Melcher PS, Johansen KL, Hendriksen P, Juul-Kristensen B. Alterations in neuromuscular function in girls with generalized joint hypermobility. BMC Musculoskelet Disord. 2016;17(1):410.

23. Junge T, Wedderkopp N, Thorlund JB, Søgaard K, Juul-Kristensen B, Kinesiology. Altered knee joint neuromuscular control during landing from a jump in 10-15 year old children with generalised joint hypermobility. A substudy of the CHAMPS-study Denmark. J Electromyogr Kinesiol. 2015;25(3):501-507.

24. Koga H, Nakamae A, Shima Y, et al. Mechanisms for noncontact anterior cruciate ligament injuries: knee joint kinematics in 10 injury situations from female team handball and basketball. Am J Sports Med. 2010;38(11):2218-2225. 
25. Lakens D. Calculating and reporting effect sizes to facilitate cumulative science: a practical primer for t-tests and ANOVAs. Front Psychol. 2013;4:863.

26. Laurent CM, Green JM, Bishop PA, et al. A practical approach to monitoring recovery: development of a perceived recovery status scale. J Strength Cond Res. 2011;25(3):620-628.

27. Lopes TJA, Simic M, Myer GD, Ford KR, Hewett TE, Pappas E. The effects of injury prevention programs on the biomechanics of landing tasks: a systematic review with meta-analysis. Am J Sports Med. 2018;46(6):1492-1499.

28. Luder G, Schmid S, Stettler M, et al. Stair climbing-an insight and comparison between women with and without joint hypermobility: a descriptive study. J Electromyogr Kinesiol. 2015;25(1):161-167.

29. Murray KJ. Hypermobility disorders in children and adolescents. Best practice and research Clinical rheumatology. 2006;20(2):329-351.

30. Pacey V, Nicholson LL, Adams RD, Munn J, Munns CF. Generalized joint hypermobility and risk of lower limb joint injury during sport: a systematic review with meta-analysis. Am J Sports Med. 2010;38(7):1487-1497.

31. Peters A, Galna B, Sangeux M, Morris M, Baker R. Quantification of soft tissue artifact in lower limb human motion analysis: a systematic review. Gait Posture. 2010;31(1):18.

32. Remvig L, Jensen DV, Ward RC. Are diagnostic criteria for general joint hypermobility and benign joint hypermobility syndrome based on reproducible and valid tests? A review of the literature. J Rheumatol. 2007;34(4):798-803.

33. Rombaut L, Malfait F, De Wandele I, et al. Muscle mass, muscle strength, functional performance, and physical impairment in women with the hypermobility type of EhlersDanlos syndrome. Arthritis Care Res. 2012;64(10):1584-1592. 
34. Rombaut L, Malfait F, De Wandele I, et al. Balance, gait, falls, and fear of falling in women with the hypermobility type of Ehlers-Danlos syndrome. Arthritis Care Res. 2011;63(10):1432-1439.

35. Saunders NA. Characteristics of the female landing pattern, University of Ballarat; 2006.

36. Scheper MC, Juul-Kristensen B, Rombaut L, Rameckers EA, Verbunt J, Engelbert RH. Disability in adolescents and adults diagnosed with hypermobility-related disorders: a meta-analysis. Arch Phys Med Rehabil. 2016;97(12):2174-2187.

37. Schultz AB. Mobility impairment in the elderly: challenges for biomechanics research. J Biomech. 1992;25(5):519-528.

38. Sigward SM, Cesar GM, Havens KL. Predictors of frontal plane knee moments during side-step cutting to 45 and 110 men and women: implications for ACL injury. Clin J Sport Med. 2015;25(6):529-534.

39. Simmonds JV, Keer RJ. Hypermobility and the hypermobility syndrome. Man Ther. 2007;12(4):298-309.

40. Simonsen EB, Tegner H, Alkjær T, et al. Gait analysis of adults with generalised joint hypermobility. Clin Biomech. 2012;27(6):573-577.

41. Singh H, McKay M, Baldwin J, et al. Beighton scores and cut-offs across the lifespan: cross-sectional study of an Australian population. Rheumatology. 2017;56(11):18571864.

42. Smith TO, Jerman E, Easton V, et al. Do people with benign joint hypermobility syndrome (BJHS) have reduced joint proprioception? A systematic review and metaanalysis. Rheumatol Int. 2013;33(11):2709-2716.

43. Smits-Engelsman B, Klerks M, Kirby A. Beighton score: a valid measure for generalized hypermobility in children. J Pediatr. 2011;158(1):119-123. 
44. Sundemo D, Senorski EH, Karlsson L, et al. Generalised joint hypermobility increases ACL injury risk and is associated with inferior outcome after ACL reconstruction: a systematic review. BMJ Open Sport Exerc Med. 2019;5(1):e000620.

45. van der Kruk E, Reijne MM. Accuracy of human motion capture systems for sport applications; state-of-the-art review. European journal of sport science. 2018;18(6):806-819.

46. Yoshida N, Kunugi S, Mashimo S, et al. Effect of forefoot strike on lower extremity muscle activity and knee joint angle during cutting in female team handball players. Sports Med. 2016;2(1):32. 



\section{Appendix}

Table A1. Directionality of joint kinematic variables in all three planes.

Sagittal plane (X)

Coronal plane (Y)

Transverse plane (Z)

\begin{tabular}{|c|c|c|c|c|c|c|}
\hline & Negative values & Positive values & Negative values & Positive values & Negative values & Positive values \\
\hline Foot $^{\mathrm{a}}$ & Toe landing & Heel landing & Eversion & Inversion & External rotation & Internal rotation \\
\hline Ankle & Plantar flexion & Dorsiflexion & Abduction & Adduction & External rotation & Internal rotation \\
\hline Knee & Extension & Flexion & Valgus & Varus & External rotation & Internal rotation \\
\hline Hip & Extension & Flexion & Abduction & Adduction & External rotation & Internal rotation \\
\hline Pelvis & Anteversion & Retroversion & Pelvis drop on stance leg & $\begin{array}{c}\text { Pelvis drop on contralateral } \\
\text { leg }\end{array}$ & Rotation towards stance leg & Rotation away from stance leg \\
\hline Trunk & Extension & Flexion & $\begin{array}{l}\text { Lateral flexion away from } \\
\text { stance leg }\end{array}$ & $\begin{array}{l}\text { Lateral flexion towards } \\
\text { stance leg }\end{array}$ & Rotation towards stance leg & Rotation away from stance leg \\
\hline
\end{tabular}

a Foot-ground angle one frame before initial contact 
Table A2. Mean \pm standard deviation values of angles $\left({ }^{\circ}\right)$ for hypermobile $(n=15)$ and non-hypermobile $(n=27)$ participants during unanticipated side-step cutting maneuvers. Refer to Table A1 for directionality of joint kinematics interpretations of minimal and maximal angle values. Significant differences $(P \leq 0.05)$ between groups are bolded.

\begin{tabular}{|c|c|c|c|c|c|c|c|}
\hline & \multirow[b]{2}{*}{ Variable } & \multicolumn{3}{|c|}{$\begin{array}{l}\text { DOMINANT LEG CUTTING }{ }^{a} \\
\end{array}$} & \multicolumn{3}{|c|}{ NON-DOMINANT LEG CUTTINGa } \\
\hline & & Hypermobile & $\begin{array}{l}\text { Non- } \\
\text { hypermobile }\end{array}$ & $P$-value & Hypermobile & $\begin{array}{l}\text { Non- } \\
\text { hypermobile }\end{array}$ & $P$-value \\
\hline \multirow{3}{*}{$\begin{array}{l}\text { Foot- } \\
\text { ground }\end{array}$} & Sagittal & $4.5 \pm 7.5$ & $3.7 \pm 6.1$ & 0.456 & $4.3 \pm 7.9$ & $5.2 \pm 5.3$ & 0.371 \\
\hline & Coronal & $-11.4 \pm 9.6$ & $-11.3 \pm 9.4$ & 0.431 & $-11.5 \pm 9.5$ & $-12.5 \pm 7.8$ & 0.297 \\
\hline & Transverse & $2.8 \pm 11.6$ & $4.9 \pm 11.5$ & 0.839 & $5.9 \pm 10.8$ & $2.5 \pm 12.1$ & 0.762 \\
\hline \multirow{9}{*}{ Ankle } & Sagittal min & $-11.1 \pm 5.5$ & $-10.6 \pm 13.0$ & 0.848 & $-9.6 \pm 5.9$ & $-14.1 \pm 6.1$ & $0.027^{*}$ \\
\hline & Sagittal max & $15.7 \pm 6.4$ & $20.5 \pm 11.1$ & 0.081 & $17.5 \pm 7.3$ & $13.0 \pm 8.2$ & 0.073 \\
\hline & Sagittal RoM & $26.8 \pm 4.5$ & $31.1 \pm 10.2$ & 0.069 & $27.1 \pm 5.5$ & $27.1 \pm 7.2$ & 0.965 \\
\hline & Coronal min & $17.8 \pm 7.7$ & $18.0 \pm 6.4$ & 0.927 & $17.4 \pm 4.8$ & $15.1 \pm 6.0$ & 0.426 \\
\hline & Coronal max & $31.7 \pm 6.3$ & $32.6 \pm 6.9$ & 0.697 & $32.2 \pm 8.2$ & $32.2 \pm 7.3$ & $0.824^{\mathrm{b}}$ \\
\hline & Coronal RoM & $14.0 \pm 8.7$ & $14.6 \pm 5.2$ & $0.868^{\mathrm{b}}$ & $14.8 \pm 8.3$ & $17.1 \pm 6.6$ & $0.364^{\mathrm{b}}$ \\
\hline & Transverse min & $-14.3 \pm 8.2$ & $-11.7 \pm 13.3$ & 0.454 & $-13.2 \pm 7.7$ & $-9.0 \pm 8.7$ & 0.115 \\
\hline & Transverse max & $-2.9 \pm 8.9$ & $-1.6 \pm 13.5$ & 0.710 & $-1.3 \pm 8.0$ & $1.2 \pm 8.5$ & 0.342 \\
\hline & Transverse RoM & $11.4 \pm 3.8$ & $10.1 \pm 3.5$ & 0.318 & $11.9 \pm 4.6$ & $10.2 \pm 3.2$ & 0.226 \\
\hline \multirow{9}{*}{ Knee } & Sagittal min & $26.4 \pm 4.9$ & $27.1 \pm 6.3$ & 0.697 & $26.5 \pm 5.4$ & $25.0 \pm 4.6$ & 0.348 \\
\hline & Sagittal max & $55.7 \pm 7.7$ & $55.9 \pm 7.1$ & 0.923 & $55.5 \pm 8.0$ & $54.8 \pm 6.0$ & 0.770 \\
\hline & Sagittal RoM & $29.3 \pm 5.5$ & $28.8 \pm 5.8$ & 0.802 & $29.0 \pm 7.6$ & $29.8 \pm 5.4$ & 0.699 \\
\hline & Coronal min & $-10.5 \pm 6.6$ & $-13.7 \pm 7.5$ & 0.159 & $-13.5 \pm 6.7$ & $-16.3 \pm 8.2$ & 0.244 \\
\hline & Coronal max & $-0.5 \pm 4.8$ & $-4.0 \pm 5.1$ & $0.032^{*}$ & $-2.2 \pm 5.4$ & $-4.7 \pm 5.4$ & 0.159 \\
\hline & Coronal RoM & $10.0 \pm 4.0$ & $9.7 \pm 3.9$ & 0.803 & $11.3 \pm 4.2$ & $11.6 \pm 4.3$ & 0.857 \\
\hline & Transverse min & $-6.5 \pm 5.9$ & $-2.0 \pm 6.6$ & $0.035^{*}$ & $-1.8 \pm 9.2$ & $-3.6 \pm 7.7$ & 0.535 \\
\hline & Transverse max & $7.1 \pm 6.0$ & $9.5 \pm 7.2$ & 0.262 & $11.5 \pm 9.5$ & $8.8 \pm 8.3$ & 0.371 \\
\hline & Transverse RoM & $13.6 \pm 3.3$ & $11.5 \pm 4.2$ & 0.079 & $13.3 \pm 3.1$ & $12.4 \pm 4.5$ & 0.459 \\
\hline \multirow{9}{*}{ Hip } & Sagittal min & $26.4 \pm 12.3$ & $26.5 \pm 12.4$ & 0.966 & $24.4 \pm 15.4$ & $24.9 \pm 15.7$ & 0.926 \\
\hline & Sagittal max & $36.6 \pm 11.5$ & $36.9 \pm 10.9$ & 0.930 & $36.6 \pm 12.7$ & $37.1 \pm 15.3$ & 0.916 \\
\hline & Sagittal RoM & $10.2 \pm 4.3$ & $10.4 \pm 4.3$ & 0.914 & $12.2 \pm 5.3$ & $12.2 \pm 4.0$ & 0.998 \\
\hline & Coronal min & $-17.6 \pm 6.9$ & $-17.6 \pm 6.9$ & 0.994 & $-20.1 \pm 8.5$ & $-18.9 \pm 6.1$ & $0.416^{\mathrm{b}}$ \\
\hline & Coronal max & $-11.0 \pm 6.0$ & $-10.8 \pm 7.0$ & 0.939 & $-11.7 \pm 9.4$ & $-12.5 \pm 6.4$ & $0.934^{\mathrm{b}}$ \\
\hline & Coronal RoM & $6.6 \pm 2.0$ & $6.8 \pm 2.3$ & 0.839 & $8.4 \pm 4.4$ & $6.4 \pm 2.4$ & 0.130 \\
\hline & Transverse min & $-9.3 \pm 10.4$ & $-10.4 \pm 8.6$ & 0.719 & $-18.7 \pm 13.3$ & $-19.8 \pm 12.5$ & 0.794 \\
\hline & Transverse max & $9.2 \pm 9.2$ & $6.7 \pm 9.1$ & 0.413 & $3.0 \pm 10.3$ & $0.2 \pm 10.9$ & 0.404 \\
\hline & Transverse RoM & $18.5 \pm 7.3$ & $17.2 \pm 6.2$ & 0.566 & $21.7 \pm 8.9$ & $20.0 \pm 6.8$ & 0.510 \\
\hline Pelvis $^{\mathrm{c}}$ & Sagittal min & $4.0 \pm 5.2$ & $3.0 \pm 9.2$ & 0.642 & $1.2 \pm 8.7$ & $1.5 \pm 9.3$ & 0.927 \\
\hline
\end{tabular}




\begin{tabular}{|c|c|c|c|c|c|c|c|}
\hline & Sagittal max & $11.7 \pm 5.5$ & $10.3 \pm 9.3$ & $0.521^{\mathrm{b}}$ & $12.3 \pm 9.1$ & $11.6 \pm 10.5$ & 0.825 \\
\hline & Sagittal RoM & $7.7 \pm 2.7$ & $7.3 \pm 2.8$ & 0.702 & $11.1 \pm 4.8$ & $10.1 \pm 4.1$ & 0.523 \\
\hline & Coronal min & $2.5 \pm 10.0$ & $2.7 \pm 25.5$ & 0.959 & $3.6 \pm 10.5$ & $7.4 \pm 6.4$ & 0.215 \\
\hline & Coronal max & $8.9 \pm 10.2$ & $9.1 \pm 22.8$ & $0.442^{\mathrm{b}}$ & $10.9 \pm 10.6$ & $14.0 \pm 7.0$ & 0.331 \\
\hline & Coronal RoM & $6.4 \pm 3.0$ & $6.4 \pm 3.8$ & 0.990 & $7.4 \pm 3.3$ & $6.6 \pm 2.9$ & 0.442 \\
\hline & Transverse min & $8.6 \pm 18.7$ & $17.1 \pm 11.6$ & 0.125 & $13.3 \pm 21.5$ & $16.1 \pm 10.6$ & 0.646 \\
\hline & Transverse max & $17.3 \pm 20.0$ & $24.9 \pm 12.6$ & 0.198 & $20.3 \pm 21.7$ & $23.7 \pm 10.2$ & 0.581 \\
\hline & Transverse RoM & $8.7 \pm 3.7$ & $7.8 \pm 2.8$ & 0.419 & $7.0 \pm 2.9$ & $7.6 \pm 2.3$ & 0.517 \\
\hline \multirow{9}{*}{ Trunk $^{c}$} & Sagittal min & $5.8 \pm 7.7$ & $9.8 \pm 8.2$ & $0.161^{b}$ & $5.6 \pm 7.7$ & $9.3 \pm 9.8$ & $0.280^{\mathrm{b}}$ \\
\hline & Sagittal max & $12.3 \pm 7.8$ & $16.1 \pm 8.1$ & $0.197^{\mathrm{b}}$ & $13.3 \pm 8.7$ & $16.7 \pm 9.6$ & $0.355^{\mathrm{b}}$ \\
\hline & Sagittal RoM & $6.5 \pm 3.8$ & $6.3 \pm 2.7$ & 0.790 & $7.7 \pm 4.1$ & $7.4 \pm 4.0$ & 0.789 \\
\hline & Coronal min & $-4.1 \pm 7.2$ & $-3.1 \pm 7.7$ & 0.668 & $-1.4 \pm 5.6$ & $-3.1 \pm 7.5$ & 0.412 \\
\hline & Coronal max & $0.4 \pm 5.7$ & $0.9 \pm 7.1$ & 0.791 & $3.1 \pm 7.2$ & $0.9 \pm 7.8$ & 0.364 \\
\hline & Coronal RoM & $4.5 \pm 2.2$ & $4.0 \pm 1.8$ & 0.473 & $4.5 \pm 3.2$ & $4.0 \pm 1.8$ & 0.583 \\
\hline & Transverse min & $0.6 \pm 14.1$ & $3.4 \pm 11.5$ & 0.516 & $1.6 \pm 18.4$ & $2.7 \pm 13.0$ & 0.839 \\
\hline & Transverse max & $11.9 \pm 14.0$ & $15.3 \pm 12.1$ & 0.436 & $12.2 \pm 18.2$ & $13.4 \pm 14.1$ & 0.836 \\
\hline & Transverse RoM & $11.3 \pm 4.6$ & $11.9 \pm 4.6$ & 0.687 & $10.6 \pm 5.2$ & $10.7 \pm 4.7$ & 0.984 \\
\hline
\end{tabular}

Abbreviations: max, maximal angle; min, minimal angle; RoM, range of motion

*significant differences $(P \leq 0.05)$ based on the multiple linear regression model.

${ }^{a}$ for right-leg dominant participants cutting to the left side was considered as dominant leg cutting and to the right side as non-dominant leg cutting.

${ }^{\mathrm{b}} P$-value from the multiple linear regression model with significant sex confounder. Note, that no analysis was performed if only sex confounder was significant. ${ }^{c}$ pelvis and trunk angles relative to the lab coordination system 